\title{
A role for ATR in the DNA damage-induced phosphorylation of p53
}

Randal S. Tibbetts ${ }^{1}$ Kathryn M. Brumbaugh, ${ }^{1}$ Josie M. Williams, ${ }^{2}$ Jann N. Sarkaria, ${ }^{2}$ William A. Cliby, ${ }^{2}$ Sheau-Yann Shieh, ${ }^{3}$ Yoichi Taya, ${ }^{4}$ Carol Prives, ${ }^{3}$ and Robert T. Abraham ${ }^{1,5}$

${ }^{1}$ Department of Pharmacology and Cancer Cell Biology, Duke University, Durham, North Carolina 27710 USA; ${ }^{2}$ Division of Oncology Research, Mayo Clinic and Foundation, Rochester, Minnesota 55902 USA; ${ }^{3}$ Department of Biological Sciences, Columbia University, New York, New York 10027 USA; ${ }^{4}$ National Cancer Center Research Institute, Tokyo, Japan

Phosphorylation at Ser-15 may be a critical event in the up-regulation and functional activation of p53 during cellular stress. In this report we provide evidence that the ATM-Rad3-related protein ATR regulates phosphorylation of Ser-15 in DNA-damaged cells. Overexpression of catalytically inactive $\operatorname{ATR}\left(\mathrm{ATR}^{\mathrm{ki}}\right)$ in human fibroblasts inhibited Ser-15 phosphorylation in response to $\gamma$-irradiation and UV light. In $\gamma$-irradiated cells, $\mathbf{A T R}^{\mathrm{ki}}$ expression selectively interfered with late-phase Ser-15 phosphorylation, whereas $\mathrm{ATR}^{\mathrm{ki}}$ blocked UV-induced Ser-15 phosphorylation in a time-independent manner. ATR phosphorylated p53 at Ser-15 and Ser-37 in vitro, suggesting that $\mathrm{p} 53$ is a target for phosphorylation by ATR in DNA-damaged cells.

Received November 9, 1998; revised version accepted December 3, 1998.

In eukaryotic cells, members of the phosphoinositide-3 kinase-related kinase (PIK) superfamily function in conserved signal transduction pathways that regulate diverse processes, including cell-cycle progression and DNA repair. The PIK family can be divided into three structurally and functionally distinct subfamilies: the TOR subfamily, the ataxia telangiectasia mutated (ATM) subfamily, and DNA-PK. Whereas the yeast and mammalian TOR proteins transduce signals required for $\mathrm{G}_{1}$-to-S-phase progression (Lawrence and Abraham 1997), the ATM/ATR and DNA-PK subfamilies are involved in DNA damage responses. ATM and ATR participate in the activation of cell-cycle checkpoints induced by DNA damage (Keith and Schreiber 1995; Zakian 1995), whereas DNA-PK acts primarily during DNA repair (Anderson and Carter 1996; Jackson 1996). Cells from AT patients, who bear loss-of-function mutations in ATM (Savitsky et al. 1995), display defective DNA damage checkpoints, hypersensitivity to ionizing radia-

[Key Words: p53; phosphorylation; ATR; PIKs; ATM] ${ }^{5}$ Corresponding author:

E-MAIL abrah008@mc.duke.edu; FAX (919) 684-8922. tion and radiomimetic drugs, and elevated frequencies of chromosomal abnormalities (Meyn 1995; Beamish et al. 1996; Lavin and Shiloh 1997). The ATM-Rad3-related protein ATR is structurally related to ATM as well as the yeast PIK family members Meclp and Rad3 (Bentley et al. 1996; Cimprich et al. 1996). Mec1p and Rad3 participate in checkpoint pathways induced by DNA replication blocks, DNA strand breaks, and other chromosomal abnormalities, which implies that ATR performs similar functions in mammalian cells (Elledge 1996; Carr 1998). A recent report demonstrated that overexpression of a catalytically inactive version of ATR ( $\left.\mathrm{ATR}^{\mathrm{ki}}\right)$ in human fibroblasts caused hypersensitivity to $\gamma$-radiation and hydroxyurea and abrogation of the radiation-induced $\mathrm{G}_{2}$ checkpoint (Cliby et al. 1998). The checkpoint defects observed in ATR ${ }^{\mathrm{ki}}$-overexpressing cells resemble those found in AT cells, suggesting that ATR and ATM carry out partially overlapping functions in response to genotoxic stress.

Accumulating evidence suggests that ATM functions upstream of the p53 tumor suppressor protein (Giaccia and Kastan 1998; Prives 1998). Functional ATM is required for optimal p53 induction and activation following cellular exposure to agents that induce DNA doublestrand breaks (DSBs) (Canman et al. 1994). Although ATM may regulate p53 activity by multiple mechanisms (Waterman et al. 1998), recent findings suggest a direct role for ATM in the DNA damage-induced phosphorylation of p53 on Ser-15 (Banin et al. 1998; Canman et al. 1998). Ser-15 is a functionally important residue within the p53 amino-terminal region (Fiscella et al. 1993), and phosphorylation of Ser-15 represents an early cellular response to a variety of genotoxic stresses (Shieh et al. 1997; Siliciano et al. 1997). p53 that has been phosphorylated at Ser-15 in vitro displays reduced binding to the inhibitor protein MDM2 (Shieh et al. 1997). Because association with MDM2 targets p53 for proteosome-mediated degradation and inhibits its transactivating function (Haupt et al. 1997; Kubbutat et al. 1997), Ser-15 phosphorylation promotes both the accumulation and functional activation of p53 in response to DNA damage. However, several lines of evidence suggest that ATM is not the only protein kinase that mediates Ser-15 phosphorylation in DNA-damaged cells. First, p53 induction (Canman et al. 1994) and Ser-15 phosphorylation (Siliciano et al. 1997) are observed in AT cell lines after UV irradiation. Second, $\gamma$-radiation triggers both Ser-15 phosphorylation and p53 accumulation in AT cells, although the kinetics of these responses are delayed when compared to normal cells (Lu and Lane 1993; Canman et al. 1994). DNA-PK also phosphorylates p53 at Ser-15 and Ser-37 in vitro (Lees-Miller et al. 1992); however p53 induction is unperturbed in DNA-PK-deficient cell lines following exposure to $\gamma$-radiation (Fried et al. 1996; Jongmans et al. 1996). These results suggest that both the modification of Ser-15 and the accumulation of p53 are controlled by multiple protein kinases, which may, in turn, be responsive to different types of DNA damage. 
In this report we provide evidence that ATR functions as an upstream regulator of p53 phosphorylation in DNA-damaged cells. In $\gamma$-irradiated human fibroblasts, overexpression of a catalytically inactive version of ATR $\left(A T R^{\mathrm{ki}}\right)$ selectively interferes with the late phase of Ser15 phosphorylation induced by $\gamma$-radiation. In contrast, the increase in Ser-15 phosphorylation provoked by UV light exposure is suppressed by ATR ${ }^{\mathrm{ki}}$ overexpression in a time-independent fashion. ATR phosphorylates p53 at both Ser-15 and Ser-37 in vitro, suggesting that ATR is directly involved in the modification of p53 in DNAdamaged cells. When considered in light of recent reports concerning ATM (Banin et al. 1998; Canman et al. 1998), these results suggest that ATR and ATM play both overlapping and independent roles in the phosphorylation of p53 during cellular exposure to genotoxic stress.

\section{Results}

The present studies addressed the possibility that ATR functions as an upstream regulator of p53 phosphorylation in cells exposed to DNA-damaging agents. The model system used for these studies was an SV40-transformed, GM847 human fibroblast cell line engineered to overexpress a Flag epitope-tagged ATR ${ }^{\mathrm{ki}}$ mutant when cultured in the presence of doxycycline (Dox) (Cliby et al. 1998). Although the presence of SV40 large T in these cells precludes studies of p53 function, we have found that cellular exposure to a variety of DNA-damaging agents ( $\gamma$-rays, UV light, and camptothecin) induces the phosphorylation of p53 at Ser-15 with time courses similar to those found in cells expressing functional p53 (data not shown). Moreover, although the determination of changes in p53 phosphorylation in normal fibroblasts is complicated by concomitant fluctuations in p53 protein levels, the expression of p53 remains relatively constant after exposure of SV40 large T-expressing fibroblasts to DNA-damaging agents. The stabilization of p53 levels by SV40 large $\mathrm{T}$ therefore facilitates the interpretation of immunoblotting results obtained with phosphospecific antibodies directed against p53.

In the absence of Dox, exposure of GM847 cells to 20 Gy of $\gamma$-radiation led to a 50 -fold increase in the $\alpha$-pSer15 immunoreactivity of p53 after $4 \mathrm{hr}$ (Fig. 1A). The radiation-induced increase in Ser-15 phosphorylation was substantially inhibited when the cells were pretreated with Dox to induce $A_{T R}{ }^{k i}$ expression. At the time of irradiation, the Dox-treated cells overexpressed the $\mathrm{ATR}^{\mathrm{ki}}$ protein by 8 - to 10 -fold relative to the endogenous ATR (Fig. 1A, top). Immunoblotting with $\alpha$-p53 revealed that the $75 \%$ reduction in pSer-15 levels in ATR ${ }^{\mathrm{ki}}$-expressing cells was not explained by an overall decrease in p53 protein levels in the irradiated cells (Fig. 1A, bottom).

To investigate the effect of $\mathrm{ATR}^{\mathrm{ki}}$ on p53 phosphorylation in greater detail, we examined the phosphorylation of Ser-15 at various times after exposure of uninduced versus Dox-treated GM847 cells to $\gamma$-irradiation. This experiment revealed that overexpression of ATR ${ }^{\mathrm{ki}}$ did not alter Ser-15 phosphorylation at times up to $1 \mathrm{hr}$ postirradiation (Fig. 1B; data not shown). However, the

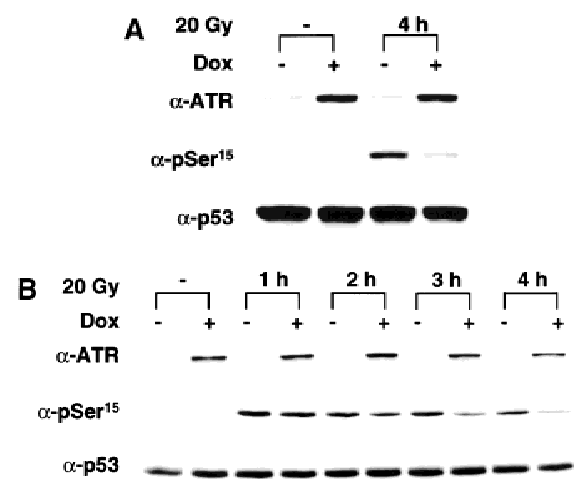

Figure 1. Overexpression of $\mathrm{ATR}^{\mathrm{ki}}$ inhibits DNA damage-induced phosphorylation of p53 on Ser-15. (A) Inhibition of $\gamma$-radiation-induced Ser-15 phosphorylation. GM847/ATR ${ }^{\mathrm{ki}}$ cells were cultured either in the absence $(-)$ or presence $(+)$ of Dox for $48 \mathrm{hr}$ to induce ATR ${ }^{\mathrm{ki}}$. Cells were either left untreated or exposed to $20 \mathrm{~Gy}$ of $\gamma$-radiation, and cell lysates were prepared after $4 \mathrm{hr}$. Immunoblots were performed with the indicated antibodies. (B) Time course of Ser-15 phosphorylation. Cells were treated as in $A$, except that cells were harvested at the indicated times after irradiation.

inhibitory effect of $\mathrm{ATR}^{\mathrm{ki}}$ overexpression on Ser-15 phosphorylation was clearly evident by $2-4 \mathrm{hr}$ after radiation treatment (Fig. 1B). These findings suggest that ATR function is more important for the maintenance of steady-state Ser-15 phosphorylation rather than for the early, inductive phase of this response. The inhibitory effects of the ATR ${ }^{\mathrm{ki}}$ mutant on p53 phosphorylation were specific for the catalytically inactive form of the protein, as inducible overexpression of wild-type ATR neither augmented nor suppressed Ser-15 phosphorylation in GM847 cells (data not shown).

The evidence presented above suggested that the catalytic activity of ATR was required for the normal phosphorylation of p53 at Ser-15 in response to $\gamma$-radiation. To test whether ATR phosphorylated p53 directly, we performed ATR immune complex kinase assays using a GST fusion protein encompassing the first 70 amino acids of human p53 (GST-p53) as the substrate. The GSTp53 protein was phosphorylated by the anti-ATR ( $\alpha$-ATR) immunoprecipitate at a level substantially above the background obtained with a preimmune serum immunoprecipitate (Fig. 2A). Mutation of Ser-15 (S15A) reduced the phosphorylation of GST-p53 by $\sim 80 \%$, and mutation of Ser-37 (S37A), which, like Ser-15 contains a Gln residue at the +1 position, resulted in a $20 \%$ decrease in phosphorylation relative to wild-type GST-p53 protein (Fig. 2A). Mutation of both Ser-15 and Ser-37 virtually abrogated the phosphorylation of GSTp53 by ATR. The phosphorylation of Ser-15 and Ser-37 by ATR was confirmed by immunoblotting the kinase reaction products with $\alpha$-pSer-15 and $\alpha$-pSer37 (Fig. 2B). These results demonstrate that both Ser-15 and Ser-37 of human p53 are phosphorylated by ATR in vitro and that Ser-15 is the predominant phosphorylation site for this protein kinase.

To confirm that phosphorylation of GST-p53 was mediated by ATR, rather than a contaminating protein ki- 


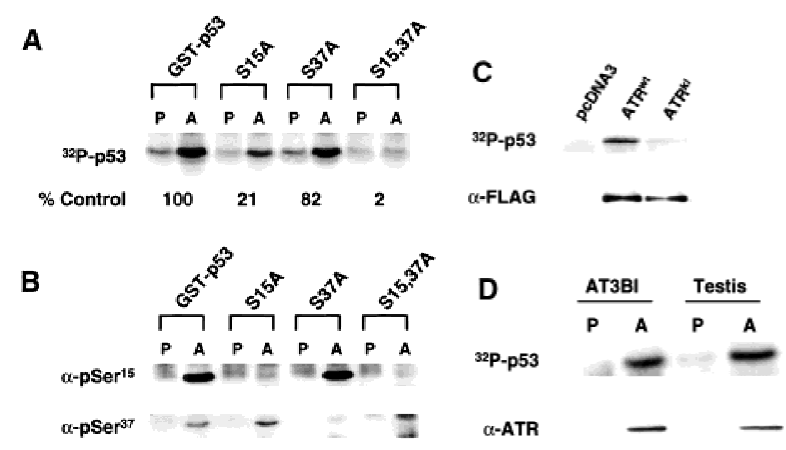

Figure 2. ATR phosphorylates p53 on Ser-15 and Ser-37. (A) Wild-type GST-p53, and p53 mutants bearing single (S15A and S37A) or double (S15A, S37A) Ser $\rightarrow$ Ala amino acid substitutions were tested as ATR substrates. ATR was immunoprecipitated from testis extracts using either preimmune rabbit serum (P) or $\alpha$-ATR (A). Numbers below each lane indicate the incorporation of $\left[{ }^{32} \mathrm{P}\right]$ phosphate into each substrate normalized to the value obtained with wild-type GST-p53. (B) Immunoreactivity of the phosphorylated wild-type and mutant GST-p53 fusion proteins with antibodies specific for phospho-Ser-15 and phospho-Ser-37, respectively. (C) Phosphorylation of p53 by ATR requires a functional kinase domain. K562 cells were transiently transfected with either pcDNA3, or plasmid constructs encoding Flag-tagged ATR (ATR ${ }^{\mathrm{wt}}$ ), or Flag-tagged ATR ${ }^{\mathrm{ki}}$. Cell extracts were immunoprecipitated with Flag $\mathrm{mAb}$, and immune complex kinase assays were performed with GST-p53 as the substrate. $(D)$ ATR kinase activity in AT cells. Detergent extracts prepared from AT3BI cells or bovine testis extract were immunoprecipitated as in $A$, and kinase assays performed as described.

nase, we transiently expressed Flag-tagged wild-type ATR $\left(\mathrm{ATR}^{\mathrm{wt}}\right.$ ) and $\mathrm{ATR}^{\mathrm{ki}}$ in K562 cells. The recombinant ATR proteins were immunoprecipitated with $\alpha$-Flag, and kinase assays were performed with GST-p53 as the substrate. These results demonstrated that ATR ${ }^{\mathrm{wt}}$ phosphorylated GST-p53, whereas the level of phosphorylation observed with ATR $^{\mathrm{ki}}$ immunoprecipitates was only marginally above background (Fig. 2C). We also noted that ATR catalytic activity was present in AT cells. ATR that was immunoprecipitated from the AT cell line AT3BI retained the ability to phosphorylate p53 in vitro, indicating that ATR catalytic activity does not require coexpression of a functional ATM polypeptide (Fig. 2D).

The observation that ATR ${ }^{\mathrm{ki}}$ inhibits Ser-15 phosphorylation, in combination with the finding that ATR phosphorylates p53 in vitro on Ser-15, implies that ATR regulates p53 in DNA-damaged cells via direct phosphorylation of Ser-15. However, it is formally possible that ATR $^{\mathrm{ki}}$ inhibits Ser-15 phosphorylation indirectly, perhaps by trans-suppression of ATM or another kinase that phosphorylates p53 at Ser-15. Two recent reports demonstrated a 1.5- to 4.0-fold increase in ATM catalytic activity within minutes after exposure of cells to $\gamma$-radiation (Canman et al. 1998) or radiomimetic drugs (Banin et al., 1998) We considered the possibility that overexpression of $\mathrm{ATR}^{\mathrm{ki}}$ might interfere with radiation-induced ATM activation, which would suggest that ATR lies upstream of ATM in a signaling pathway. In the absence of $\mathrm{ATR}^{\mathrm{ki}}$ overexpression, ATM catalytic activ- ity, as measured by the in vitro phosphorylation of GSTp53, was elevated 1.3-fold at $1 \mathrm{hr}$ after exposure of GM847 cells to 20 Gy $\gamma$-radiation (Fig. 3). A similar increase in ATM activity was obtained in ATR ${ }^{\mathrm{ki}}$-overexpressing cells. We noted that the levels of ATM protein were reduced by $\sim 20 \%$ in Dox-treated cells, in the absence or presence of radiation exposure (Fig. 3, bottom). Whether this decrease in ATM protein reflects a biologically relevant effect of $\mathrm{ATR}^{\mathrm{ki}}$ overexpression is unclear. Nonetheless, these results support the conclusion that ATR kinase activity is not required for the activation of ATM in $\gamma$-irradiated cells. Moreover, the findings argue against the possibility that the inhibitory effects of $\mathrm{ATR}^{\mathrm{ki}}$ on Ser-15 phosphorylation are due to trans-dominant suppression of ATM.

Previous studies demonstrated that UV-induced DNA damage signals to p53 via an ATM-independent pathway (Canman et al. 1994; Siliciano et al. 1997; Giaccia and Kastan 1998). Inhibition of UV-light induced Ser-15 phosphorylation in $\mathrm{ATR}^{\mathrm{ki}}$-overexpressing fibroblasts would implicate ATR as the pivotal PIK family member in this checkpoint pathway. We examined the status of Ser-15 phosphorylation at various times after exposure of uninduced versus Dox-treated GM847 cells to $50 \mathrm{~J} / \mathrm{m}^{2}$ of UV radiation. This experiment revealed that overexpression of $\mathrm{ATR}^{\mathrm{ki}}$ strongly inhibited UV-induced Ser-15 phosphorylation (Fig. 4). Intriguingly, whereas ATR ${ }^{\mathrm{ki}}$ preferentially suppressed the plateau phase of Ser-15 phosphorylation in $\gamma$-irradiated cells (Fig. 1B), it inhibited both the inductive and plateau phases of Ser-15 phosphorylation in cells exposed to UV light (Fig. 4). In uninduced cells, Ser-15 phosphorylation was maximal at $1 \mathrm{hr}$ after UV irradiation, and this response was inhibited by $80 \%$ in $\mathrm{ATR}^{\mathrm{ki}}$-overexpressing cells. In contrast, overexpression of ATR ${ }^{\mathrm{ki}}$ did not substantially inhibit Ser-15 phosphorylation in cells exposed to the topoisomerase I inhibitor, camptothecin (CPT), indicating that overexpression of ATR ${ }^{\mathrm{ki}}$ does not result in global inhibition of DNA damage-induced Ser-15 phosphorylation (data not shown). When combined with the observation that $\mathrm{ATR}^{\mathrm{ki}}$ does not inhibit ATM catalytic activity, our results strongly suggest that the inhibition of UV- and $\gamma$-radiation-induced Ser-15 phosphorylation by catalytically inactive ATR reflects a dominant-negative effect of the mutated protein on the checkpoint functions of endogenous ATR.

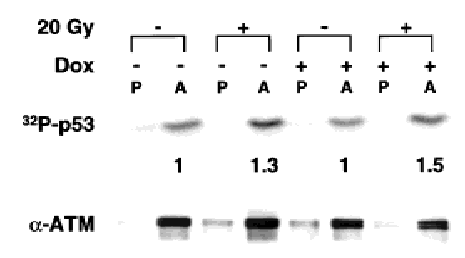

Figure 3. $\gamma$-Radiation-induced ATM activation in ATR ${ }^{\mathrm{ki}}$ overexpressing cells. GM847/ATR ${ }^{\mathrm{ki}}$ cells were cultured and cells treated as in Fig. 1A. After $1 \mathrm{hr}$, ATM was immunoprecipitated and ATM kinase assays were performed as in Fig. 2A. Numbers below sample lanes are as in Fig. 2A. Levels of ATM protein were determined by immunoblotting with $\alpha$-ATM (bottom). 


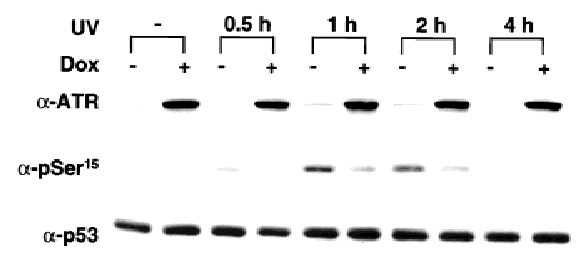

Figure 4. Effects of $\mathrm{ATR}^{\mathrm{ki}}$ overexpression on Ser-15 phosphorylation induced by UV light. GM847/ATR ${ }^{\mathrm{ki}}$ cells were cultured as in Fig. 1A and were either left untreated or exposed to $50 \mathrm{~J} / \mathrm{m}^{2} \mathrm{UV}$ light; cell lysates were prepared at the indicated time intervals. Detergent-soluble proteins were separated by SDS-PAGE and were immunoblotted with the indicated antibodies.

\section{Discussion}

The observation that overexpression of ATR ${ }^{\mathrm{ki}}$ inhibited $\gamma$-radiation-induced phosphorylation of p53 at Ser-15 indicates that ATR is an upstream signaling element in the pathway leading to Ser-15 phosphorylation in $\gamma$-irradiated cells. In addition, immunoprecipitated ATR phosphorylates the amino-terminal region of p53, suggesting that the interaction between ATR and p53 is direct. While this manuscript was in preparation, Canman et al. (1998) reported that ATR phosphorylates p53 at Ser-15. We have confirmed and extended this observation by showing that ATR phosphorylates p53 at two functionally important sites, Ser-15 and Ser-37. Based on the recent report that ATM does not modify Ser-37 in p53 (Banin et al. 1998), our results suggest that the substrate specificities of ATR and ATM are partially, but not entirely, overlapping.

Two recent reports demonstrated that ATM has a direct role in the phosphorylation of Ser-15 in response to $\gamma$-radiation (Canman et el. 1998) and radiomimetic agents (Banin et al. 1998). Because overexpression of ATR $^{\mathrm{ki}}$ preferentially inhibited the later, steady-state phase of Ser-15 phosphorylation, rather than the early, inductive phase of this response, we hypothesize that ATM and ATR function sequentially during the induction and maintenance of Ser-15 phosphorylation in $\gamma$-irradiated cells. This hypothesis is supported by two experimental observations. First, ATM catalytic activity is activated two- to fourfold within minutes of DNA strand breakage, compatible with a function during the early phase of p53 phosphorylation (Banin et al. 1998). Second, $\gamma$-radiation-induced p53 accumulation (Canman et al. 1994), and Ser-15 phosphorylation (Siliciano et al. 1997) are delayed, but not abrogated, in ATM-deficient cells. We propose that the delayed p53 induction and Ser-15 phosphorylation observed in DNA-damaged AT cells are at least partly attributable to the activity of ATR. The sequential recruitment of ATM and ATR into the p53 phosphorylation pathway may be a consequence of dynamic changes in the initiating lesion during the cellular response to $\gamma$-radiation-induced DNA damage. The primary genetic lesions induced by $\gamma$-radiation (e.g., DSBs and SSBs) may activate ATM efficiently, but subsequent processing of the lesions may be required for the recognition of altered DNA structures by ATR. An alternative hypothesis posits that ATM and ATR are both recruited to the initial DNA strand break but that ATM catalytic activity is up-regulated more robustly and subsides more quickly than ATR catalytic activity. Only when ATM activation diminishes does the contribution of ATR to Ser-15 phosphorylation become prominent. The model that ATM and ATR function sequentially during the response to damaged DNA has an interesting precedent in the process of meiotic recombination, during which ATR and ATM are selectively associated with asynapsed and synapsed regions of meiotic chromatin (Keegan et al. 1996).

In contrast to the results obtained with $\gamma$-irradiated cells, overexpression of $\mathrm{ATR}^{\mathrm{ki}}$ strongly interfered with UV light-induced Ser-15 phosphorylation at both the early and late stages of this response (Fig. 4). This finding may reflect a predominant role for ATR in checkpoint activation by UV-induced DNA lesions, including modified DNA bases, thymine dimers, and excision repair intermediates. Participation of ATR in UV-induced damage responses is consistent with the finding that ectopic expression of ATR complements the UV-sensitive phenotype of a Saccharomyces cerevisiae mec1 mutant (Bentley et al. 1996). A role for ATR in mediating UV responses is also suggested by two reports that $\mathrm{ATR}^{\mathrm{ki}}$ confers increased UV sensitivity when expressed in mammalian cells (Cliby et al. 1998; Wright et al. 1998). Intriguingly, UV light induces phosphorylation of p53 at Ser-37, and this phosphorylation event may regulate the sequence-specific DNA-binding activity of p53 (Sakaguchi et al. 1998). Therefore, the ability of ATR to phosphorylate p53 at Ser-37 in vitro suggests that the regulatory interaction between p53 and ATR may not be limited to phosphorylation of Ser-15.

Because AT cells are not hypersensitive to UV light and neither UV-induced p53 accumulation /Canman et al. 1994) nor Ser-15 phosphorylation (Siliciano et al. 1997) is defective in AT cell lines, the participation of ATR in UV responses implies a divergence of function between these two PIK family members. Supportive evidence for this conclusion stems from the demonstration that overexpressed $\mathrm{ATR}^{\mathrm{ki}}$ does not confer a significant radio-resistant DNA synthesis phenotype on GM847 cells (Cliby et al. 1998). We also noted that overexpression of ATR ${ }^{k i}$ did not substantially inhibit Ser-15 phosphorylation induced by the topoisomerase I inhibitor, CPT (R.S. Tibbetts et al., unpubl.), suggesting that another kinase such as ATM or DNA-PK is predominantly responsible for Ser-15 phosphorylation after recognition of the DNA damage caused by CPT. Collectively, the available data strongly support the conclusion that ATM and ATR carry out both overlapping and distinct signaling functions during cellular responses to different types of genotoxic stress.

\section{Materials and methods}

Cell culture and antisera

SV40-immortalized GM847 cells and the SV40-immortalized AT cell line AT3BI were grown in Dulbecco's modified Eagle medium containing $10 \%$ fetal calf serum (FCS; Hyclone) supplemented with 2 mm L-gluta- 
mine. K562 cells were maintained in RPMI-1640 medium containing $10 \%$ FCS. The generation, maintenance, and characterization of GM847 cells that express $\mathrm{ATR}^{\mathrm{wt}}$ or $\mathrm{ATR}^{\mathrm{ki}}$ under control of the bacterial tet operator have been described previously (Cliby 1998). Induction of $\mathrm{ATR}^{\mathrm{wt}}$ or $\mathrm{ATR}^{\mathrm{ki}}$ was accomplished by plating out $3 \times 10^{5}$ cells in 100 $\mathrm{mm}$ dishes in culture medium containing $1 \mu \mathrm{g} / \mathrm{ml}$ Dox for $48 \mathrm{hr}$. Where indicated, cells were irradiated with a ${ }^{137} \mathrm{Cs} \gamma$-ray source or exposed to a 310-nm wavelength UV source. The viabilities of DNA-damaged cells were not affected over the brief time courses used in these studies (data not shown).

ATR-specific antiserum was generated by immunizing rabbits with a GST fusion protein containing amino acids $400-460$ of ATR. The resulting $\alpha$-ATR antiserum was purified with protein G-Sepharose (Pharmacia) and was used at a concentration of $1 \mu \mathrm{g} / \mathrm{ml}$ for immunoblotting. $\alpha-\mathrm{Hu}-$ man p53 (Ab-6) and $\alpha$-ATM (Ab-3) were purchased from Oncogene Research Products. The methodology used to generate the $\alpha$-p53-phosphoserine-15 antibody ( $\alpha$-pSer-15) has been described (Shieh et al. 1997). The $\alpha$-pSer-37 polyclonal antibody was raised against a KLH-conjugated phosphopeptide VLSPLP(pS)QAMDDLC and was affinity purified as described previously (Kitagawa et al. 1996). The Flag (M2)-specific mAb was purchased from Kodak-IBI.

\section{Plasmid constructs and transfections}

Two ATR constructs bearing inactivating amino acid substitutions in the kinase domain were used in this study. The catalytically inactive ATR mutant used for Dox-inducible expression in GM847 cells contains an inactivating Asp-2475 $\rightarrow$ Ala substitution in the ATP-binding cleft (Cliby et al. 1998). The second ATR mutant contains a Lys-2327 $\rightarrow$ Arg substitution and was used for expression in K562 cells. Both constructs are denoted as ATR ${ }^{\mathrm{ki}}$. To generate a plasmid encoding the amino terminus of p53, a PCR-generated fragment spanning nucleotides 1-210 of the human p53 coding region was subcloned into pGEX-2T. The resulting plasmid encodes the amino-terminal 70 amino acids of p53 fused to GST. For transient transfections, $1 \times 10^{7} \mathrm{~K} 562$ cells were subjected to a $340 \mathrm{~V}$ $10-\mathrm{msec}$ electropulse in the presence of $45 \mu \mathrm{g}$ of plasmid DNA using a BTX square wave electroporator (BTX, San Diego, CA). The transfected cells were then cultured for $24 \mathrm{hr}$ prior to harvest.

Immunoprecipitations, immunoblotting, and kinase assays

Cell extracts were prepared by resuspending cells in lysis buffer $(25 \mathrm{~mm}$ HEPES at $\mathrm{pH} 7.4,150 \mathrm{~mm} \mathrm{NaCl}, 1.5 \mathrm{~mm} \mathrm{MgCl}_{2}, 1$ mm EGTA, $0.2 \mathrm{~mm}$ sodium orthovanadate, $20 \mathrm{~nm}$ microcystin, $50 \mathrm{~mm} \beta$-glycerophosphate, $0.5 \%$ Triton X-100) with protease inhibitors $(10 \mu \mathrm{g} / \mathrm{ml}$ leupeptin, $5 \mu \mathrm{g}$ $\mathrm{ml}$ pepstatin A, $5 \mu \mathrm{g} / \mathrm{ml}$ aprotinin). Forty micrograms of protein per sample was then analyzed by SDS-PAGE and immunoblotting with the appropriate antibodies.

An ATR-enriched testis extract was prepared by homogenizing 5 grams of bovine testis in $10 \mathrm{ml}$ of homogenization buffer $(50 \mathrm{~mm}$ Tris at $\mathrm{pH} 7.4$ $0.3 \mathrm{~m} \mathrm{NaCl}, 1 \mathrm{~mm}$ EDTA) with protease inhibitors. The homogenate was centrifuged at $140,000 \mathrm{~g}$ and fractionated with $30 \%$ ammonium sulfate as described previously (Sabers et al. 1995). For ATR kinase assays, ATR was immunoprecipitated with $3 \mu \mathrm{g}$ of $\alpha$-ATR from $1 \mathrm{mg}$ of cell or testis extract. Immune complexes were washed twice in lysis buffer containing $1 \mathrm{~m} \mathrm{NaCl}$ and then twice in knase buffer $(10 \mathrm{~mm}$ HEPES at $\mathrm{pH} 7.4,50 \mathrm{~mm} \mathrm{NaCl}, 10 \mathrm{~mm} \mathrm{MgCl}_{2}$ ). The immunoprecipitates were resuspended in $40 \mu \mathrm{l}$ of kinase buffer containing $1 \mathrm{~mm}$ dithiothreitol, 0.5 mm sodium orthovanadate, $20 \mathrm{~nm}$ microcystin, $20 \mathrm{~mm} \beta$-glycerophosphate, protease inhibitors, $1 \mu \mathrm{g}$ of the indicated substrate, $10 \mu \mathrm{m}$ ATP, and $20 \mu \mathrm{Ci}$ of $\left[\gamma_{-}{ }^{32} \mathrm{P}\right] \mathrm{ATP}(3500 \mathrm{Ci} / \mathrm{mmole})$. Kinase reactions were terminated and analyzed as described (Brunn et al. 1996). ATM kinase assays were performed by a similar procedure. GM847 cells were harvested by trypsinization, washed with PBS, and subjected to two freezethaw cycles. Cell pellets were resuspended in cell lysis buffer containing $0.2 \%$ Tween-20 in place of $0.5 \%$ Triton X-100, and the lysates were clarified by centrifugation. Immunoprecipitations were carried out with $750 \mu \mathrm{g}$ of extract protein and $2.5 \mu \mathrm{g}$ of either $\alpha$-ATM or nonimmune rabbit IgG. The ATM immunoprecipitates were prepared for kinase assays according to procedures described above, except that the ATM immunoprecipitates were washed with lysis buffer containing $150 \mathrm{~mm}$ $\mathrm{NaCl}$ in place of $1 \mathrm{M} \mathrm{NaCl}$. Levels of ${ }^{32} \mathrm{P}$ incorporation into p53 substrates were quantitated using a Molecular Dynamics STORM 840 imaging system.

\section{Acknowledgments}

This work was supported by grants from the National Institutes of Health (NIH;CA76193 and CA52995 to R.T.A. and CA58316 to C.P.) and funds from the Admadjaja Thymoma Research Unit. R.S.T is a Fellow of the Leukemia Society of America. K.M.B was supported by a multidisciplinary basic research training grant from the NIH (CA09441-15).

The publication costs of this article were defrayed in part by payment of page charges. This article must therefore be hereby marked 'advertisement' in accordance with 18 USC section 1734 solely to indicate this fact.

\section{References}

Anderson, C.W. and T.H. Carter. 1996. The DNA-activated protein kinase-DNA-PK. Curr. Top. Microbiol. Immunol. 217: 91-111.

Banin, S., L. Moyal, S.Y. Shieh, Y. Taya, C.W. Anderson, L. Chessa, N.I. Smorodinsky, C. Prives, Y. Reiss, Y. Shiloh, and Y. Ziv. 1998. Enhanced phosphorylation of p53 by ATM in response to DNA damage. Science 281: 1674-1677.

Beamish, H., R. Williams, P. Chen, and M.F. Lavin. 1996. Defect in multiple cell cycle checkpoints in ataxia-telangiectasia postirradiation. J. Biol. Chem. 271: 20486-20493.

Bentley, N.J., D.A. Holtzman, G. Flaggs, K.S. Keegan, A. DeMaggio, J.C. Ford, M. Hoekstra, and A.M. Carr. 1996. The Schizosaccharomyces pombe rad3 checkpoint gene. EMBO J. 15: 6641-6651.

Brunn, G.J., J. Williams, C. Sabers, G. Wiederrecht, J.C. Lawrence, Jr., and R.T. Abraham. 1996. Direct inhibition of the signaling functions of the mammalian target of rapamycin by the phosphoinositide 3-kinase inhibitors, wortmannin and LY294002. EMBO J. 15: 5256-5267.

Canman, C.E., D.S. Lim, K.A. Cimprich, Y. Taya, K. Tamai, K. Sakaguchi, E. Appella, M.B. Kastan, and J.D. Siliciano. 1998. Activation of the ATM kinase by ionizing radiation and phosphorylation of p53. Science 281: 1677-1679.

Canman, C.E., A.C. Wolff, C.Y. Chen, A.J. Fornace, Jr., and M.B. Kastan. 1994. The p53-dependent G1 cell cycle checkpoint pathway and ataxia-telangiectasia. Cancer Res. 54: 5054-5058.

Carr, A.M. 1998. Analysis of fission yeast DNA structure checkpoints. Microbiology 144: 5-11

Cimprich, K.A., T.B. Shin, C.T. Keith, and S.L. Schreiber. 1996. cDNA cloning and gene mapping of a candidate human cell cycle checkpoint protein. Proc. Natl. Acad. Sci. 93: 2850-2855.

Cliby, W.A., C.J. Roberts, K.A. Cimprich, C.M. Stringer, J.R. Lamb, S.L. Schreiber, and S.H. Friend. 1998. Overexpression of a kinase-inactive ATR protein causes sensitivity to DNA-damaging agents and defects in cell cycle checkpoints. EMBO J. 17: 159-169.

Elledge, S.J. 1996. Cell cycle checkpoints: Preventing an identity crisis Science 274: 1664-1672.

Fiscella, M., S.J. Ullrich, N. Zambrano, M.T. Shields, D. Lin, S.P. LeesMiller, C.W. Anderson, W.E. Mercer, and E. Appella. 1993. Mutation of the serine 15 phosphorylation site of human p 53 reduces the ability of p53 to inhibit cell cycle progression. Oncogene 8: 1519-1528.

Fried, L.M., C. Koumenis, S.R. Peterson, S.L. Green, P. van Zijl, J. Allalunis-Turner, D.J. Chen, R. Fishel, A.J. Giaccia, J.M. Brown, and C.U. Kirchgessner. 1996. The DNA damage response in DNA-dependent protein kinase-deficient SCID mouse cells: Replication protein A hyperphosphorylation and p53 induction. Proc. Nat1. Acad. Sci. 93: $13825-13830$.

Giaccia, A.J. and M.B. Kastan. 1998. The complexity of p53 modulation emerging patterns from divergent signals. Genes \& Dev. 12: 29732983.

Haupt, Y., R. Maya, A. Kazaz, and M. Oren. 1997. Mdm2 promotes the rapid degradation of p53. Nature 387: 296-299.

Jackson, S.P. 1996. DNA damage detection by DNA dependent protein kinase and related enzymes. Cancer Surv. 28: 261-279.

Jongmans, W., M. Artuso, M. Vuillaume, H. Bresil, S.P. Jackson, and J. Hall. 1996. The role of Ataxia telangiectasia and the DNA-dependent protein kinase in the p53-mediated cellular response to ionising radiation. Oncogene 13: 1133-1138.

Keegan, K.S., D.A. Holtzman, A.W. Plug, E.R. Christenson, E.E. Brainerd, G. Flaggs, N.J. Bentley, E.M. Taylor, M.S. Meyn, S.B. Moss, A.M. Carr, T. Ashley, and M.F. Hoekstra. 1996. The Atr and Atm protein kinases associate with different sites along meiotically pairing chromosomes. Genes \& Dev. 10: 2423-2437. 
Keith, C.T. and S.L. Schreiber. 1995. PIK-related kinases: DNA repair, recombination, and cell cycle checkpoints. Science 270: 50-51.

Kitagawa, M., H. Higashi, H.K. Jung, I. Suzuki-Takahashi, M. Ikeda, K. Tamai, J. Kato, K. Segawa, E. Yoshida, S. Nishimura, and Y. Taya. 1996. The consensus motif for phosphorylation by cyclin D1-Cdk4 is different from that for phosphorylation by cyclin A/E-Cdk2. EMBO $J$. 15: 7060-7069.

Kubbutat, M.H., S.N. Jones, and K.H. Vousden. 1997. Regulation of p53 stability by Mdm2. Nature 387: 299-303.

Lavin, M.F. and Y. Shiloh. 1997. The genetic defect in ataxia-telangiectasia. Annu. Rev. Immunol. 15: 177-202.

Lawrence, J.C.J. and R.T. Abraham. 1997. PHAS/4E-BPs as regulators of mRNA translation and cell proliferation. Trends Biochem. Sci. 22: $345-349$

Lees-Miller, S.P., K. Sakaguchi, S.J. Ullrich, E. Appella, and C.W. Anderson. 1992. Human DNA-activated protein kinase phosphorylates serines 15 and 37 in the amino-terminal transactivation domain of human p53. Mol. Cell. Biol. 12: 5041-5049.

Lu, X. and D.P. Lane. 1993. Differential induction of transcriptionally active p53 following UV or ionizing radiation: Defects in chromosome instability syndromes? Cell 75: 765-778.

Meyn, M.S. 1995. Ataxia-telangiectasia and cellular responses to DNA damage. Cancer Res. 55: 5991-6001.

Prives, C. 1998. Signaling to p53: Breaking the MDM2-p53 circuit. Cell 95: 5-8.

Sabers, C.J., M.M. Martin, G.J. Brunn, J.M. Williams, F.J. Dumont, G. Wiederrecht, and R.T. Abraham. 1995. Isolation of a protein target of the FKBP12-rapamycin complex in mammalian cells. J. Biol. Chem. 270: 815-822.

Sakaguchi, K., J.E. Herrera, S. Saito, T. Miki, M. Bustin, A. Vassilev, C.W. Anderson, and E. Appella. 1998. DNA damage activates p53 through a phosphorylation-acetylation cascade. Genes \& Dev. 12: 2831-2841.

Savitsky, K., A. Bar-Shira, S. Gilad, G. Rotman, Y. Ziv, L. Vanagaite, D.A. Tagle, S. Smith, T. Uziel, S. Sfez, M. Ashkenazi, L. Pecker, M. Frydman, R. Harnkik, R.P. Sankhavaram, A. Simmons, G.A. Clines, A. Sartiel, R.A. Gatti, L. Chessa, O. Sanal, M.F. Lavin, N.G.J. Jaspers, M.R. Taylor, C.F. Arlett, T. Miki, S.M. Weissman, M. Lovett, F. Collins, and Y. Shiloh. 1995. A single ataxia telangiectasia gene with a product similar to PI-3 kinase. Science 268: 1749-1753.

Shieh, S.Y., M. Ikeda, Y. Taya, and C. Prives. 1997. DNA damage-induced phosphorylation of p53 alleviates inhibition by MDM2. Cell 91: 325334.

Siliciano, J.D., C.E. Canman, Y. Taya, K. Sakaguchi, E. Appella, and M.B. Kastan. 1997. DNA damage induces phosphorylation of the amino terminus of p53. Genes \& Dev. 11: 3471-3481.

Waterman, M.J., E.S. Stavridi, J.L. Waterman, and T.D. Halazonetis 1998. ATM-dependent activation of p53 involves dephosphorylation and association with 14-3-3 proteins. Nat. Genet. 19: 175-178.

Wright, J.A., K.S. Keegan, D.R. Herendeen, N.J. Bentley, A.M. Carr, M.F. Hoekstra, and P. Concannon. 1998. Protein kinase mutants of human ATR increase sensitivity to UV and ionizing radiation and abrogate cell cycle checkpoint control. Proc. Natl. Acad. Sci. 95: 7445-7450.

Zakian, V.A. 1995. ATM-related genes: What do they tell us about functions of the human gene? Cell 82: 685-687. 


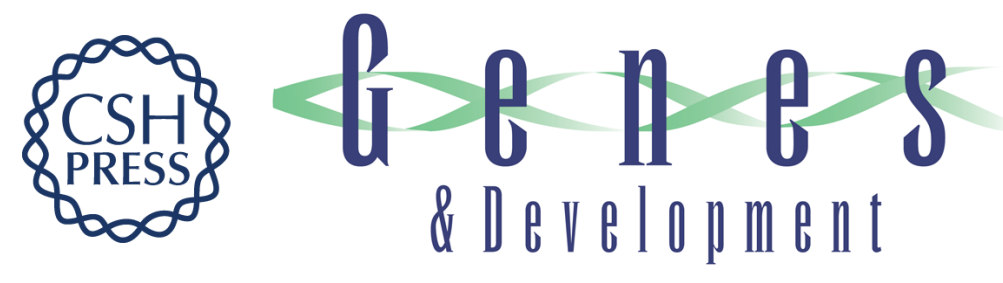

\section{A role for ATR in the DNA damage-induced phosphorylation of p53}

Randal S. Tibbetts, Kathryn M. Brumbaugh, Josie M. Williams, et al.

Genes Dev. 1999, 13:

References This article cites 34 articles, 17 of which can be accessed free at: http://genesdev.cshlp.org/content/13/2/152.full.htmI\#ref-list-1

License

Email Alerting

Receive free email alerts when new articles cite this article - sign up in the box at the top Service right corner of the article or click here.

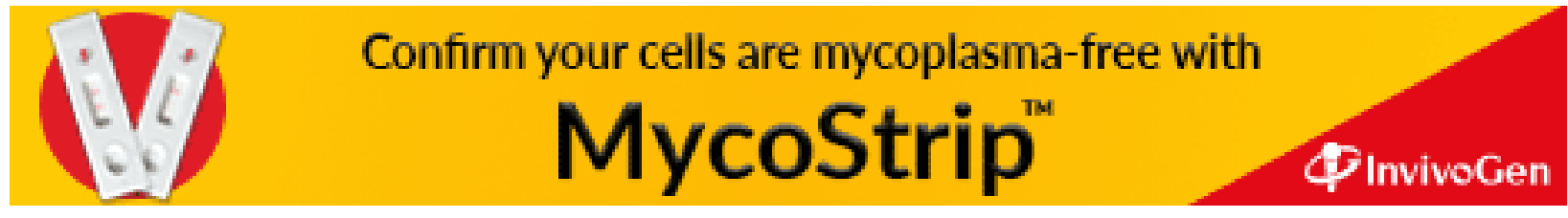

